\title{
Chemoradiation therapy with S-1 for primary squamous cell carcinoma of the rectum: report of three cases
}

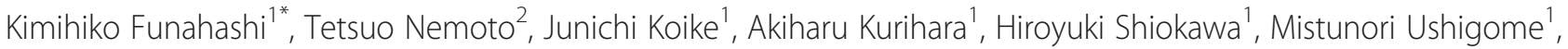

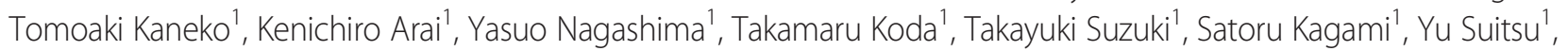
Hironori Kaneko ${ }^{1}$ and Toshikazu Shibuya ${ }^{2}$

\begin{abstract}
Purpose: Although successful treatment of squamous cell carcinoma (SCC) of the rectum using chemoradiation therapy (CRT) has been reported, a standard protocol has yet to be established. The aim is to ascertain the effectiveness of CRT with S-1 for three patients with SCC of the rectum.

Case presentation: We treated three female patients complaining of rectal bleeding. The patients were diagnosed as having primary SCC of the rectum by means of routine examinations; one of them was a very rare case because of the presence of two lesions in the lower rectum. We treated the patients using CRT with S1 at a radiation dose of 1.8 Gy/fraction given five times weekly (Monday to Friday) to a median dose of 59.4 (45 to 59.4) Gy; S-1 ( $80 \mathrm{mg} / \mathrm{m}^{2} /$ day) was administered orally during radiation therapy. One of three patients had an adverse event involving massive hemorrhage from the tumor. All patients exhibited an excellent response to CRT with S-1; two patients had a complete response, and one patient had a partial response and underwent a posterior pelvic exenteration with advancement flap reconstruction as a salvage treatment. Pathological examination of the resected specimen and lymph nodes revealed no tumor cells indicating a pathological complete response. In this series, the response rate was $100 \%$.
\end{abstract}

Conclusions: We suggest that CRT with S-1 be chosen as the first-line therapy for SCC of the rectum. However, a large study will be required to establish a safe and effective regimen.

Keywords: Squamous cell carcinoma; Rectum; Chemoradiation therapy; S-1

\section{Background}

Primary squamous cell carcinoma (SCC) of the anorectum is a very rare disease and there have been few reports regarding SCC in the rectum. Nowadays, chemoradiation therapy (CRT) with 5-fluorouracil (5-FU) plus mitomycin$\mathrm{C}$ (MMC) is the recommended treatment for SCC of the anus based on the findings from a small number of clinical trials [1-3]; surgery is considered as being a salvage treatment. An optimal treatment for primary SCC of the rectum has not been established because of the lack of randomized studies. The choice of the treatment

\footnotetext{
* Correspondence: kingkong@med.toho-u.ac.jp

'Department of General and Gastroenterological Surgery, Toho University Medical Center, Omori Hospital, 6-11-1 Omorinishi, Otaku, Tokyo 143-8541, Japan

Full list of author information is available at the end of the article
}

depends on the tumor characteristics, namely, size, location, depth of tumor cell invasion, and distant metastasis. Recently, some studies have reported that CRT might also be effective in the treatment of primary SCC of the rectum [4-9]. Oral fluoropyrimidines including S-1, tegafur-uracil (UFT), and capecitabine have been developed as a therapeutic alternative to the venous infusion of 5-FU. S-1 is an oral anticancer drug composed of tegafur (a prodrug of 5-FU), 5-chloro-2, 4dihydropyrimidine (CDHP; gimeracil), and potassium oxonate that has the following benefits. It increases the blood 5-FU concentration by inhibiting the metabolism of 5-FU by means of dihydropyrimidine dehydrogenase, and it also enhances the radiation response of colon cancer as compared with 5-FU. In the present case report, we 
describe three patients with SCC of the rectum that responded to CRT with $\mathrm{S}-1$.

\section{Case presentation}

\section{Patient 1}

A 54-year-old woman was diagnosed as having primary $\mathrm{SCC}$ of the rectum at another institution. Although abdominoperineal resection (APR) was proposed as a radical treatment at the institution, the patient consulted our institution about alternative treatments including CRT. A colonoscopy revealed the presence of an ulcerative lesion in the lower rectum. Histological analysis of biopsies taken at the time of the colonoscopy revealed SCC. There were no lesions detected at any site other than the rectum using computed tomography $(\mathrm{CT})$ and magnetic resonance imaging (MRI). Lymph node metastasis was found in the mesorectum. Finally, we diagnosed the lesions as primary SCC (cT3 N2a M0, cStage III B) of the rectum. We proposed laparoscopic intersphincteric resection (ISR) for the lesion as a radical treatment, but the patient refused the operation and requested CRT. Therefore, CRT with S-1 was administered. Radiation therapy (RT) at a dose of $1.8 \mathrm{~Gy} /$ fraction was given five times weekly (Monday to Friday) to a total dose of 59.4 Gy; $\mathrm{S}-1\left(80 \mathrm{mg} / \mathrm{m}^{2} /\right.$ day $)$ was administered orally for a total of 55 days (33 days during RT and 22 days alone). The planned CRT with S-1 was achieved without adverse events. The tumor marker, squamous cell carcinoma antigen (SCC Ag), had normalized after CRT with S-1 from a level of 9.3 to $0.9 \mathrm{ng} / \mathrm{ml}$. Colonoscopy revealed the complete response of the lesions, and there were no tumor cells detected in the biopsies taken during colonoscopy (Figure 1). The patient was regularly followed up every 6 months, but there were no findings of recurrence and anorectal dysfunction over a follow-up period of 3 years and 8 months.

\section{Patient 2}

An 84-year-old woman visited our institution complaining of bloody stools. Digital rectal examination at the outpatients department of our institution revealed a tumor located at about $4 \mathrm{~cm}$ from the anal verge. Additionally, a colonoscopy detected another lesion in the lower rectum. Histological evaluation of biopsies taken at the time of the colonoscopy revealed SCC. There were no lesions detected at any other site using CT and MRI. Finally, we diagnosed the lesions as primary SCC of the rectum (cT3 NO MO, cStage II A). We proposed laparoscopic ISR for these lesions as a radical treatment, but the patient refused the operation because of her advanced age. Consequently, CRT with S-1 was administered for the treatment of these lesions. RT at a dose of $1.8 \mathrm{~Gy} /$ fraction was delivered five times weekly (Monday to Friday) to a total dose of 59.4 Gy, and S-1 ( $80 \mathrm{mg} / \mathrm{m}^{2} /$ day) was given orally for a total of 50 days (33 days during radiation therapy and 17 days alone). The planned CRT with S-1 was achieved safely without adverse events. The tumor marker, SCC Ag, had normalized after CRT with S-1 from a level of 6.8 to 0.9 $\mathrm{ng} / \mathrm{ml}$. Colonoscopy showed a complete response for both lesions, and there were no tumor cells in biopsies taken in the colonoscopy (Figure 2). The patient was regularly

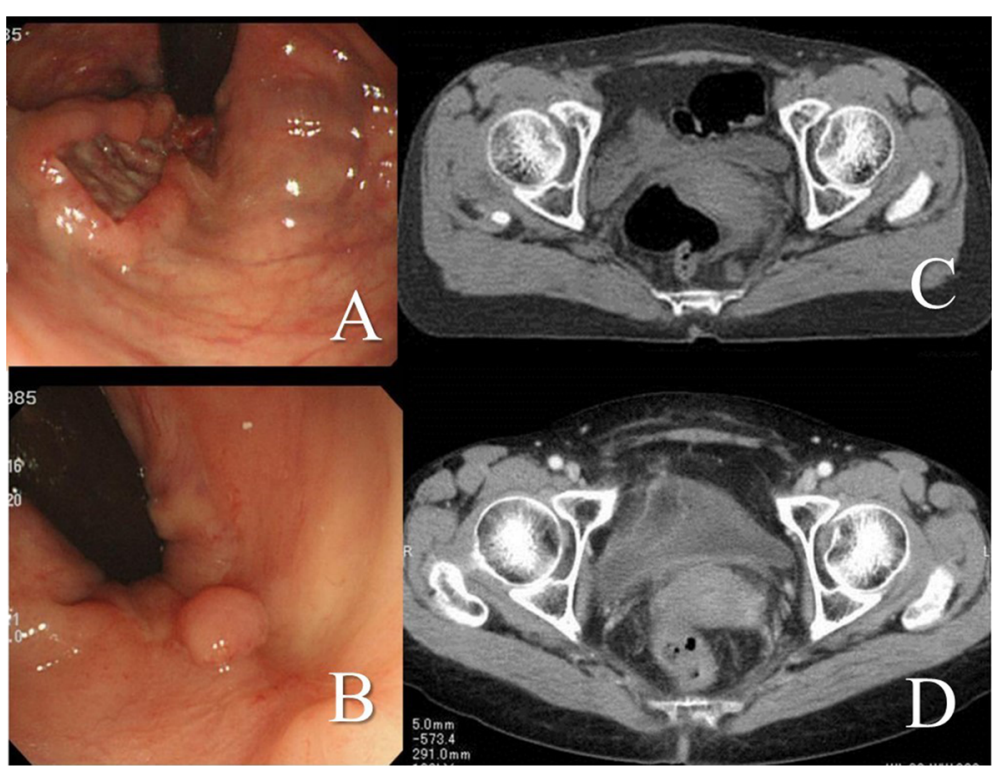

Figure 1 Effectiveness of chemoradiation therapy with S-1 for patient 1 evaluated by colonoscopy and computed tomography. Colonoscopy was showing an ulcerative lesion in the lower rectum (A). Lymph node metastasis in the mesorectum was suspected using computed tomography (C). After chemoradiation therapy with S-1, colonoscopy showed a polypoid lesion (B). Biopsies revealed that there were no tumor cells, and lymph node metastasis had disappeared (D). 


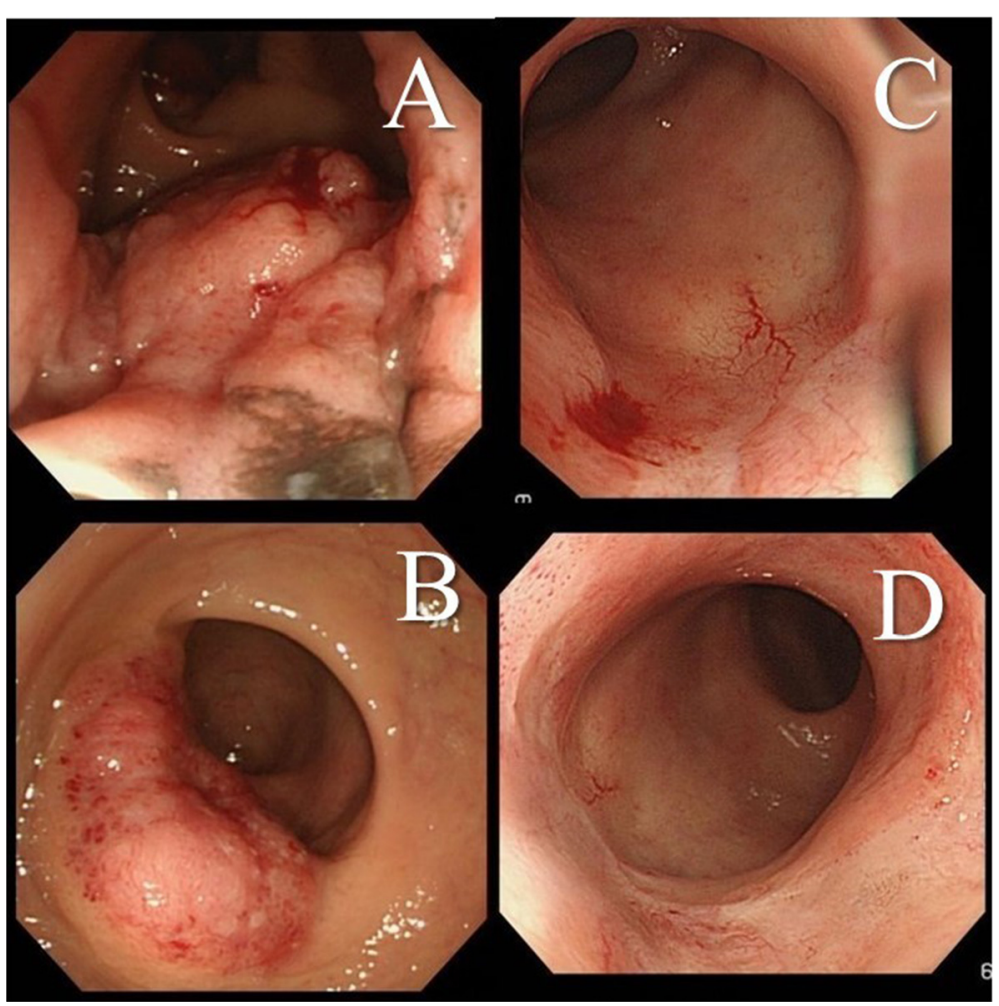

Figure 2 Colonoscopy findings of patients $\mathbf{2}$. Colonoscopy images from patient 2. Two lesions are present in the rectum (A, B). No lymph node metastasis was detected using imaging. After radiation therapy at a total dose of 59.4 Gy in combination with S-1, the lesions disappeared (C, D). The patient was regularly followed up at 6-month intervals, but no recurrence was found over a follow-up period of 2 years and 1 month.

followed up at 6-month intervals, and there were no findings of recurrence and anorectal dysfunction over a follow-up period of 2 years and 1 month.

\section{Patient 3}

A 64-year-old woman visited our institution complaining of analgia. We suspected rectal cancer from the findings of digital examination and immediately hospitalized the patient to observe the lesion and perform open biopsy under spinal anesthesia. It was found that the tumor in the lower rectum had massively invaded the perineum but there were no findings including anal involvement and fistulous tract lined by rectal tumor. Histological analysis of biopsies revealed SCC. Additionally, MRI showed invasion of the levator ani and the vagina (T4b), with lymph node metastases involvement including the inguinal lymph nodes. However, there was no distant metastasis. We diagnosed the lesion as primary SCC of the rectum. The SCC was staged as cT4b N2b M0, cStage III C using the TNM classification. CRT with S-1 for the locally advanced lesion was planned as a primary treatment. $\mathrm{RT}$ at a dose of $1.8 \mathrm{~Gy} /$ fraction was delivered five times weekly (Monday to Friday) to a total dose of 59.4 Gy, and S-1 (80 $\mathrm{mg} / \mathrm{m} 2 /$ day) was given orally. However, during treatment, the patient developed a massive hemorrhage from the primary lesion and required a blood transfusion. The adverse event was considered as grade 3 in the common terminology criteria for adverse events version 4.0. Finally, RT of a total dose of 45 Gy and S-1 ( $80 \mathrm{mg} / \mathrm{m} 2 /$ day) for a total of 30 days were performed. After CRT with S-1, the level of SCC Ag had decreased from a level of 54.3 to 1.2 $\mathrm{ng} / \mathrm{ml}$. Evaluation using MRI indicated that the size of the primary lesion had decreased (Figure 3). Consequently, we performed a posterior exenteration with advancement flap reconstruction as salvage therapy. Pathological findings revealed no tumor cells in either the resected specimen or the lymph nodes. Therefore, the patient was judged to have achieved a pathological complete response. After leaving the hospital, the patient was followed up regularly at our outpatient department. She complained of lumbar pain at 1 year after treatment. MRI of the spine showed bone metastasis. RT was administered to palliate the lumbar pain induced by bone metastasis. Finally, the patient died of bone and liver metastases at 1 year and 2 months after surgery.

\section{Discussion}

We treated three patients with SCC of the rectum in our institution between 2000 and 2013 (Table 1). The therapy for SCC of the rectum was approved by the Toho 


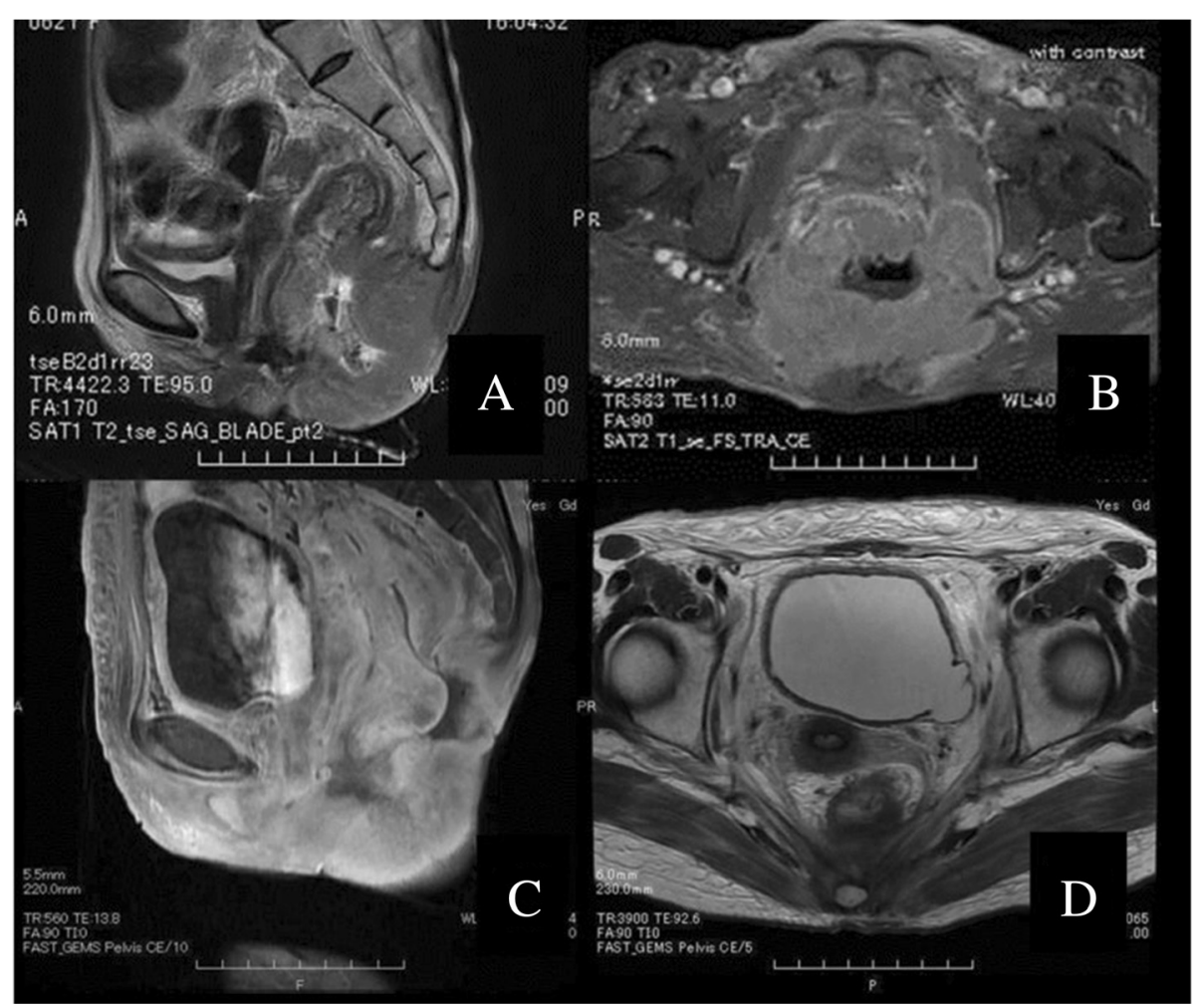

Figure 3 Magnetic resonance imaging of patient 3. Magnetic resonance image of patient 3 with squamous cell carcinoma of the rectum (A, B). The tumor was diagnosed as being at clinical stage T4b N2b M0. The patient received chemoradiation therapy with S-1 (C, D), and then, a posterior pelvic exenteration with advancement flap reconstruction was performed as salvage therapy. Pathological findings revealed no tumor cells in either the resected specimen or the lymph nodes (i.e., a pathological complete response).

University Medical Center Omori Hospital Institutional Review Board (No. 26-231). All of the patients were female and complained of rectal bleeding. Colonoscopy revealed a tumor located in the lower rectum, and histological analysis of biopsies taken at the time of colonoscopy indicated SCC. CT and MRI examinations did not detect lesions at any other site. Finally, the lesions were diagnosed as primary SCC of the rectum. The occurrence of SCC in the colon and rectum is much rarer than in that the anus. In particular, the occurrence of two lesions in the rectum is extremely rare. The mechanism of the development of SCC in the rectum remains elusive. Human papillomavirus (HPV) has been associated with many squamous cell carcinomas such as oral, vaginal, esophageal, and anal cancer and so on. It is possible that SCC of the rectum is associated with HPV infection as well, but there are no firm evidences for a cause or relationship between infection with HPV and SCC of the rectum [10,11]. In addition, several cases have been reported in patients with ulcerative colitis [12-15] and in patients with infections including Schistosomiasis [16] and Entamoeba histolytica [17].

Currently, treatment for SCC of the rectum depends on tumor size, location, depth of invasion, lymph node involvement, and the presence of distant organ metastasis. Local excision is appropriate for T1 or selected T2 tumor, and low anterior resection or abdominoperineal resection is required for advanced tumor. Dyson et al. [18], however, reported that prognosis for patients with SCC of the rectum who received surgical treatment was poor. Surgical treatment also accompanies some problems such as surgical site infection, leakage, and urinary/sexual complications. Some researchers have reported several cases treated using CRT as the primary therapy or in conjunction with surgery [14,15,19-24]. Recently, Clark et al. [4], Rasheed et al. [5], and Sturgeon et al. [25] reported the success of CRT in the treatment of SCC of the rectum. Their regimens involved primary 5-FU-based treatment together with either MMC or cisplatin, which were the same regimens as used for SCC of the anus. Additionally, some experimental treatments using CRT with S-1 + cisplatin, S-1 + MMC, and S-1 alone for SCC of the anus have been reported in Japanese studies [26-34]. These studies found that all patients treated using CRT with S-1 alone had an excellent response to treatment (Table 2). S-1 is an oral anticancer drug that has the following benefits. S-1 increases the blood 5-FU concentration by inhibiting the metabolism of 5 -FU by means 
Table 1 Patients treated with chemoradiation therapy with S-1 Number Gender Age Location Size (mm) cStage RT (gray/fraction) C

\begin{tabular}{lllllll} 
CT & $\begin{array}{l}\text { Adverse events } \\
\text { (CTCAE v4.0) }\end{array}$ & $\begin{array}{l}\text { SCC Ag before } \\
\text { CRT }\end{array}$ & $\begin{array}{l}\text { SCC Ag after } \\
\text { CRT }\end{array}$ & Operation & Response & Prognosis \\
\hline S-1 alone None & 9.3 & 0.9 & - & CR & $\begin{array}{l}\text { Disease-free for 3 years } \\
8 \text { months }\end{array}$ \\
S-1 alone None & 6.8 & 0.9 & - & CR & $\begin{array}{l}\text { Disease-free for 2 years } \\
1 \text { month }\end{array}$ \\
S-1 alone Hemorrhage (G-3) & 54.3 & 1.2 & PPE & PCR & $\begin{array}{l}\text { Bone and liver metastasis } \\
\text { at 1 year 2 months }\end{array}$
\end{tabular}

$\mathrm{Rb} \quad 125$

$\mathrm{RT}$, radiation therapy; CT, chemotherapy; CTCAE, common terminology criteria for adverse events; SCC Ag, squamous cell carcinoma antigen; CRT, chemoradiation therapy; Ra, rectum above the peritoneal reflection; $\mathrm{Rb}$, rectum below the peritoneal reflection; $\mathrm{CR}$, complete response; $\mathrm{PPE}$, posterior pelvic exenteration; $\mathrm{PCR}$, pathological complete response. 
Table 2 Reported cases of squamous cell carcinoma of the anus treated chemoradiation therapy with S-1

\begin{tabular}{|c|c|c|c|c|c|c|c|c|c|}
\hline Author & & Gender & Age & Location & cStage & RT (Gy) & Chemotherapy & Response & Prognosis \\
\hline Miyamoto S et al. [26] & 2009 & $\mathrm{~F}$ & 61 & $A C$ & IV & 30 & $\mathrm{~S}-1+\mathrm{CDDP}$ & $C R$ & Disease-free for 20 months \\
\hline Kuga $\mathrm{Y}$ et al. [27] & 2009 & $\mathrm{~F}$ & 76 & $A C$ & III & 50 & $\mathrm{~S}-1+\mathrm{CDDP}$ & $C R$ & NR \\
\hline \multirow[t]{3}{*}{ Shiozawa M et al. [28] } & 2010 & $\mathrm{~F}$ & 48 & $A C$ & III & 60 & $\mathrm{~S}-1+\mathrm{MMC}$ & $C R$ & Disease-free for 2 years 7 months \\
\hline & & $\mathrm{F}$ & 65 & $A C$ & III & 55.8 & $S-1+M M C$ & $C R$ & Disease-free for 2 years 4 months \\
\hline & & $\mathrm{F}$ & 71 & $A C$ & III & 58.0 & $\mathrm{~S}-1+\mathrm{MMC}$ & $C R$ & Disease-free for 8 months \\
\hline Hata T et al. [29] & 2011 & $\mathrm{~F}$ & 53 & $A C$ & I & 45 & S-1 alone & $C R$ & NR \\
\hline Baba $\mathrm{H}$ et al. [30] & 2011 & $\mathrm{~F}$ & 79 & $A C$ & III & 66 & S-1 alone & $C R$ & Disease-free for 10 months \\
\hline Nitori $\mathrm{N}$ et al. [31] & 2011 & $\mathrm{~F}$ & 58 & $A C$ & IV & 30 & $\mathrm{~S}-1+\mathrm{CDDP}$ & NR & Dead at 16 months \\
\hline Kuroda M et al. [32] & 2012 & $\mathrm{~F}$ & 81 & $A C$ & IV & 50.4 & $\mathrm{~S}-1+\mathrm{CDDP}$ & $C R$ & Disease-free for 1 year 3 months \\
\hline Sato H et al. [33] & 2012 & $\mathrm{~F}$ & 83 & $A C$ & $\|$ & 60 & S-1 alone & $C R$ & $\begin{array}{l}\text { Local recurrence at } 9 \text { months and dead at } \\
15 \text { months after CRT }\end{array}$ \\
\hline Murata K et al. [34] & 2012 & $\mathrm{~F}$ & 76 & $A C$ & $\|$ & 60 & S-1 alone & $C R$ & Recurrence at 2 years \\
\hline
\end{tabular}

$\mathrm{RT}$, radiation therapy; $\mathrm{AC}$, anal canal; $\mathrm{CR}$, complete response; NR, not reported.

of dihydropyrimidine dehydrogenase (DPD) and shows significant effectiveness to adenocarcinoma with highDPD activity of the stomach [35-37], pancreas [38,39], biliary tract [40-42], and so on $[43,44]$. Moreover, S-1 is more effective as a tumor radiation response enhancer than 5-FU $[45,46]$. In reports by Vezeridis et al. [47] and Maritinez-Gonzalez et al. [20], disease control for SCC of the rectum treated using 5-FU and RT was not sufficient. In our series, RT was delivered at a total dose of $59.4 \mathrm{~Gy}$ in $1.8 \mathrm{~Gy} /$ fraction 5 days weekly (Monday to Friday) over a period of 33 days, and S-1 $\left(80 \mathrm{mg} / \mathrm{m}^{2} /\right.$ day) was given orally during RT. Patients 1 and 2 were able to safely undergo treatment with $\mathrm{S}-1$, whereas patient 3 was not. Regarding the effectiveness of treatment, all patients had an excellent tumor response; there was a complete response in two patients and a partial response in one. Although patient 3 required a posterior pelvic exenteration with advancement flap reconstruction as a salvage therapy, pathological findings revealed no tumor cells in either the resected specimen or the lymph nodes. Therefore, the response rate was $100 \%$ in this series. Phan et al. [48] and Lukan et al. [49] have reported on the treatment of refractory SCC of the anus using cetuximab. Molecular-targeted therapy such as cetuximab for SCC with an epithelial growth factor receptor might be useful in the treatment of a refractory SCC, such as that seen in patient 3 .

\section{Conclusions}

The results suggested that CRT with $\mathrm{S}-1$ was chosen as the first-line therapy for SCC of the rectum; although, surgery might be an effective salvage therapy. Evaluation of this modality in a large series of patients with SCC of the rectum will be required to establish safety and efficacy.

\section{Consent}

Informed consent was obtained from the patients for publication of this case report and any accompanying images. A copy of the written consent is available for review by the Editor-in-Chief of this journal.

\section{Abbreviations}

5-FU: 5-Fluorouracil; APR: abdominoperineal resection; CRT: chemoradiation therapy; CT: computed tomography; DPD: dihydropyrimidine dehydrogenase; HPV: human papillomavirus; ISR: intersphincteric resection; MMC: mitomycin-C; MRI: magnetic resonance imaging; RT: radiation therapy; SCC: squamous cell carcinoma; SCC Ag: Squamous cell carcinoma antigen.

\section{Competing interests}

The authors declare that they have no competing interests.

\section{Authors' contributions}

$\mathrm{TN}, \mathrm{TOS}$, and KF carried out the histological evaluation of squamous cell carcinoma of the rectum. JK, HS, MU, TOK, KA, AK, and YN were assistants for operations for these three patients. TAK, TAS, SK, YS, and HK helped to draft the manuscript. All authors read and approved the final manuscript.

\section{Author details}

'Department of General and Gastroenterological Surgery, Toho University Medical Center, Omori Hospital, 6-11-1 Omorinishi, Otaku, Tokyo 143-8541, Japan. ${ }^{2}$ Department of Pathology, Toho University Medical Center, Omori Hospital, 6-11-1 Omorinishi, Otaku, Tokyo 143-8541, Japan.

Received: 18 November 2014 Accepted: 27 January 2015

Published online: 10 February 2015

\section{References}

1. UKCCR Anal Cancer Trial Working Party. Epidermoid anal cancer: results from the UKCCCR randomized trial of radiotherapy alone versus radiotherapy, 5-fluorouracil, and mitomycin. Lancet. 1996;348:1049-54.

2. Flam M, John M, Pajak TF, Petrelli N, Myerson R, Doggett $S$, et al. Role of mitomycin in combination with fluorouracil and radiotherapy, and of salvage chemoradiation in the definitive non surgical treatment of epidermoid carcinoma of the anal canal: result of phase III randomized intergroup study. J Clin Oncol. 1996;14:2527-39.

3. Bartelink H, Roelofsen F, Eschwege F, Rougier P, Bosset JF, Gonzalez DG, et al. Concomitant radiotherapy and chemotherapy is superior to radiotherapy alone in the treatment of locally advanced anal cancer, result of a phase III randomized trial of the European Organization for Research and Treatment of Cancer Radiotherapy and Gastrointestinal Cooperative Groups. J Clin Oncol. 1997;15:2040-9. 
4. Clark J, Cleator S, Goldin R, Lowdell C, Darzi A, Ziprin P. Treatment of primary rectal squamous cell carcinoma by primary chemoradiotherapy: should surgery still be considered a standard of care? Eur J Cancer. 2008:44:2340-3.

5. Rasheed S, Yap T, Zia A, McDonald PJ, Glynee-Jones R. Chemo-radiotherapy: an alternative to surgery for squamous cell carcinoma of the rectum-report of six patients and literature review. Colorectal Dis. 2009;11:191-7.

6. Jeong BG, Kim DY, Kim SY. Concurrent chemoradiotherapy for squamous cell carcinoma of the rectum. Hepatogastroenterology. 2013;60:512-6.

7. Al Hallak MN, Hage-Nassar G, Mouchli A. Primary submucosal squamous cell carcinoma of the rectum diagnosed by endoscopic ultrasound: case report and literature review. Case Rep Gastroenterol. 2010;24:243-9.

8. lannacone E, Dionisi F, Musio D, Caiazzo R, Raffetto N, Banelli E. Chemoradiation as definitive treatment for primary squamous cell cancer of the rectum. World J Radiol. 2010;28:329-33.

9. Ferreira $A O$, Loureiro AL, Marques $V$, Sousa HT. Primary squamous cell carcinoma of the most distal rectum: a dilemma in origin and management BMJ Case Resp. 2014. doi:10.1136/bcr-2013-201156

10. Sotlar K, Koveker G, Aepinus C, Selinka HC, Kandolf R, Bultmann B. Human papillomavirus type 16-associated primary squamous cell carcinoma of the rectum. Gastroenterology. 2001;120:988-94.

11. Kong CS, Welton ML, Longacre TA. Role of human papillomavirus in squamous cell metaplasia-dysplasia-carcinoma of the rectum. Am J Surg Pathol. 2007;31:919-25.

12. Comer TP, Beahrs $\mathrm{OH}$, Dockerty MB. Primary squamous cell carcinoma and adenoacanthoma of the colon. Cancer. 1971;28:1111-7.

13. Hohm WH, Jackman RJ. Squamous cell carcinoma of the rectum complicating ulcerative colitis: report of two cases. Mayo Clin Proc. 1964;39:249-51.

14. Zirkin RM, Mccord DL. Squamous cell carcinoma of the rectum: report of a case complicating chronic ulcerative colitis. Dis Colon Rectum. 1963;6:370-3.

15. Michelassi F, Montag AG, Block GE. Adenosquamous-cell carcinoma in ulcerative colitis. Dis Colon Rectum. 1988:31:323-6.

16. Wiener MF, Polayes SH, Yidi R. Squamous carcinoma with schistosomiasis of the colon. Am J Gastroenterol. 1962;37:48-54.

17. Williams GT, Blackshaw AJ, Morson BC. Squamous carcinoma of the colorectum and its genesis. J Pathol. 1979;129:139-47.

18. Dyson T, Draganov PV. Squamous cell cancer of the rectum. World J Gastroenterol. 2009;15:4380-6.

19. Schneider II TA, Birkett DH, Vernava III AM. Primary adenosquamous and squamous cell carcinoma of the colon and rectum. Int J Colorectal Dis. 1992;7:144-7.

20. Martinez-Gonzalez MD, Takahashi T, Leon-Rodriguez E, Gamboa-Dominguez A, Lome C, Garcia-Blanco MC, et al. Case report of primary squamous carcinoma of the rectum. Rev Invest Clin. 1996:48:453-6.

21. Copur $S$, Ledakis $P$, Novinski D, Mleczko KL, Frankforter S, Bolton M, et al. Squamous cell carcinoma of the colon with an elevated serum squamous cell carcinoma antigen responding to combination chemotherapy. Clin Colorectal Cancer. 2001;1:55-8.

22. Gelas T, Peyrat P, Francois Y, Gerard JP, Baulieux J, Gilly FN, et al. Primary squamous-cell carcinoma of the rectum: report of six cases and review of the literature. Dis Colon Rectum. 2002;45:1535-40.

23. Theodosopoulos TK, Marinis AD, Dafnios NA, Vassiliou JG, Samanides LD, Carvounis $\mathrm{EE}$, et al. Aggressive treatment of metastatic squamous cell carcinoma of the rectum to the liver: a case report and a brief review of the literature. World J Surg Oncol. 2006:4:49.

24. Kassir R, Baccot S, Bouarioua N, Petcu CA, Dubois J, Boueil-Bourlier A, et al. Squamous cell carcinoma of middle rectum: literature review. Int J Surg Case Rep. 2014:5:80-90.

25. Sturgeon JD, Crane CH, Krishnan S, Minsky BD, Skibber JM, Rodriguez-Bigas MA et al. Definitive chemoradiation for squamous cell carcinoma of the rectum. Am J Clin Oncol. 2014. doi: 10. 1097/COC. 0000000000000126

26. Miyamoto S, Maeda Y, Hishima T, Sasaki T. Case of higher efficacy by chemoradiotherapy for anal canal cancer from left cervix metastases to lymph nodes. Gan To Kagaku Ryoho. 2009;36:329-32.

27. Kuga Y, Tanaka T, Arita M, Usui Y, Okanobu H, Numata Y, et al. A case of effective chemoradiotherapy using S-1 and CDDP for left inguinal lymph node metastasis of anal canal carcinoma. Gan To Kagaku Ryoho. 2009;36:1923-5.

28. Shiozawa M, Nishimura K, Nonaka T, Yoshii T, Nakayama N, Motohashi O, et al. Three cases of radiotherapy combined with S-1 and mitomycin C for anal canal squamous cell carcinomas. Gan To Kagaku Ryoho. 2010;37:2941-3.
29. Hata T, Ohara N, Masuike Y, Okamoto K, Hata T, Fujino S, et al. Squamous cell carcinoma of the anal canal showing pathological complete response after S-1 plus radiotherapy - a case report. Gan To Kagaku Ryoho. 2011;38:2110-2.

30. Baba H, Kuwabara H, Wakabayashi M, Nakamura H, Sanada T, Baba H, et al. A case report of chemoradiotherapy combined with S-1 responding to squamous cell carcinoma of the anal canal. Gan To Kagaku Ryoho. 2011;38:2280-2.

31. Nitori N, Kato Y, Kato A, Deguchi T, Okada A, Kojima M, et al. Clinica experience with chemoradiotherapy comprising S-1 plus low-dose cisplatin in a patient with stage IV anal cancer. Anticancer Res. 2011;31:3983-9.

32. Kuroda M, Hirai R, Ikeda E, Tsuji H, Takagi S, Yamano T, et al. A case of a geriatric patient with stage IV anal canal cancer showing complete response to chemoradiation therapy. Gan To Kagaku Ryoho. 2012;39:1926-8.

33. Sato H, Koide $Y$, Matsuoka H, Honda $K$, Shiota M, Endo T, et al. Our experiences of anal squamous cell carcinoma treated by chemoradiotherapy. Gan To Kagaku Ryoho. 2012;39:2179-81.

34. Murata K, Okamura S, Wada Y, Makino S, Kato R, Nishigaki T, et al. Treatment of inguinal lymph node recurrence after chemo-radiation for anal canal squamous carcinoma. Gan To Kagaku Ryoho. 2012;39:2275-7.

35. Sakuramoto S, Sasako M, Yamaguchi T, Kinoshita T, Fujii M, Nashimoto A, et al. ACTS-GC group adjuvant chemotherapy for gastric cancer with S-1, an oral fluoropyrimidine. N Engl J Med. 2007;357:1810-20.

36. Yang J, Zhou Y, Min K, Yao Q, Xu CN. S-1-based vs non-S-1-based chemotherapy in advanced gastric cancer: a meta-analysis. World J Gastroenterol. 2014;20:11886-93.

37. Sasako M, Terashima M, Ichikawa W, Ochiai A, Kitada K, Kurahashi I et al. Impact of the expression of thymidylate synthase and dihydropyrimidine dehydrogenase genes on survival in stage II/III gastric cancer. Gastric Cancer. 2014; doi:10.1007/s10120-014-0413-8

38. Ueno H, loka T, Ikeda M, Ohkawa S, Yanagimoto H, Boku N, et al. Randomized phase III study of gemcitabine plus S-1, S-1 alone, or gemcitabine alone in patients with locally advanced and metastatic pancreatic cancer in Japan and Taiwan: GEST study. J Clin Oncol. 2013;31:1640-8.

39. Sudo K, Nakamura K, Yamaguchi T. S-1 in the treatment of pancreatic cancer World J Gastroenterol. 2014;20:1510-8.

40. Furuse J, Okusaka T, Boku N, Ohkawa S, Sawaki A, Masumoto T, et al. S-1 monotherapy as first-line treatment in patients with advanced biliary tract cancer: a multicenter phase II study. Cancer Chemother Pharmacol. 2008;62:849-55.

41. Sasaki T, Isayama H, Nakai $Y$, Ito $Y$, Yasuda I, Toda $N$, et al. A randomized phase II study of gemcitabine and S-1 combination therapy versus gemcitabine monotherapy for advanced biliary tract cancer. Cancer Chemother Pharmacol. 2013;7:937-9.

42. Morizane C, Okusaka T, Mizusawa J, Takashima A, Ueno M, Ikeda M, et al. Randomized phase II study of gemcitabine plus S-1 versus S-1 in advanced biliary tract cancer: a Japan Clinical Oncology Group trial (JCOG 0805). Cancer Sci. 2013:104:1211-6.

43. Fukushima M, Morita M, Ikeda K, Nagayama S. Population study of expression of thymidylate synthase and dihydroprymidine dehydrogenase in patients with solid tumors. Int J Mol Med. 2003;12:839-44.

44. Cao C, Zhang X, Kuang M, Gu D, He M, Chen J, et al. Survival benefit from Sas compared to fluorouracil in Asian patients with advanced gastrointestinal cancer: a meta-analysis. Cancer Sci. 2014;105:1008-14.

45. Tatsumi K, Fukushima M, Shirasaka T, Fujii S. Inhibitory effects of pyrimidine, barbituric acid and pyridine derivatives on 5-fluorouracil degradation in rat liver extracts. Jpn J Cancer Res. 1987:78:748-55.

46. Van den Brande J, Schoffski P, Schellens JH. EORTC Early Clinical Studies Group early phase II trial of S-1 in patients with advanced or metastatic colorectal cancer. Br J Cancer. 2003;88:648-53.

47. Vezeridis MP, Herrera LO, Lopez GE, Ledesma EJ, Mittleman A. Squamous-cell carcinoma of the colon and rectum. Dis Colon Rectum. 1983;26:188-91.

48. Phan LK, Hoff PM. Evidence of clinical activity for cetuvimab combined with irinotecan in a patient with refractory and canal squamous-cell carcinoma: report of a case. Dis Colon Rectum. 2007;50:395-8.

49. Lukan N, Strobel P, Willer A, Kripp M, Dinter D, Mai S, et al. Cetuximab-based treatment of metastatic anal cancer: correlation of response with KRAS mutational status. Oncology. 2009:77:293-9. 